\title{
The Construction of TRIZ Teaching Curriculum System Based on the Cultivation of College Students' Innovative Ability--A Case Study on the Innovation Teaching of Automobile Specialty
}

\author{
Jia Cui \\ Guilin University of Aerospace Technology, Guangxi Normal University, Guilin541004, China. \\ 121408011@qq.com
}

Keyword: TRIZ theory; Ability of innovation and entrepreneurship; Teaching curriculum system.

\begin{abstract}
TRIZ theory provides scientific and systematic analysis and problem solving methods and theories. Mastering TRIZ theory can break the mindset and improve the ability of innovation and entrepreneurship. The TRIZ theory is applied to the practice of College Students' innovation and entrepreneurship education system, and the training practice platform based on professional education is constructed to guide teachers and students to participate in innovation and practice innovation, which can provide an educational practice path for the training of innovative applied talents.
\end{abstract}

\section{Introduction}

Education is the first place to cultivate innovative talents. Colleges and universities are the main place to cultivate innovative talents. The reform and innovation of education and teaching in Colleges and universities play a key role in improving the cultivation of students' innovative ability and innovative thinking. It is a major issue in the construction of innovative countries and the key to the construction of application-oriented universities.

\subsection{TRIZ Theory.}

The TRIZ theory, the theory of inventive problem solving, known as the "magic touch", is a former Soviet scientist, inventor Genrich and Archie Schuler research group in 1946 on the analysis of the proposed world about 2500000 high level on the basis of the patent [1]. The method is: will need to resolve the practical problems of abstract and convergence for the standard model, using TRIZ tools to get the solutions of the TRIZ model, and further into the final solution of specific problems, or continue to form the final satisfactory results.

After half a century of development, TRIZ theory has become the best tool to guide innovation practice in the world recognized, not only suitable for technology research and development, and is widely used in personnel training[2]. In recent years, experts and scholars from China's small universities and enterprises began to introduce TRIZ to carry out research and application work. In this regard, there are Hebei University of Technology, Tsinghua University, and Furan University and so on. Beijing Institute of Technology, Beijing University of Chemical Technology, Beijing University of Technology and other more than 30 universities have begun to introduce TRIZ to carry out innovative education, especially in mechanical engineering and other science and engineering courses have begun to involve.

\subsection{Taking the Automobile Innovation Practice Group Teaching as an Example to Explain the} TRIZ Theory Teaching.

The emergence of new technology in the process of automobile development and the 40 innovative principles of TRIZ theory have a good confirmation. To better illustrate the TRIZ theory teaching, the following will be the Automobile Engineering Specialty Formula car manufacturing Team innovation practice teaching process as an example to explain.

First step: The teacher describes the question: how do the passengers feel comfortable when they pass the uneven road? 
If the suspension stiffness is too large, although the automobile vibration attenuation time is short, but the damping effect of automobile is obvious, so that passengers feel severe vibration, is not conducive to passenger comfort; If the suspension stiffness is too low, although the passengers do not feel the violent vibration, but the vehicle vibration attenuation time is longer, which is not conducive to the vehicle handling stability.

Second steps: Students into the problem understanding: the car through the uneven road, can reduce the car vibration in a short time, and to ensure that passengers have better riding comfort.

Third steps: Teachers put forward technical contradictions, students think about the key elements of the problem: suspension is not conducive to ride comfort, but suspension stiffness is too low, is not conducive to vehicle handling stability.

The corresponding technical contradiction is that: (1) change the parameters of hope: automotive vibration attenuation time (by changing the suspension spring stiffness to change the stiffness of the suspension); (2) the parameter that causes deterioration: the harmful factors produced by the object (too fast attenuation of car vibration is unfavorable to the comfort of passengers); (3) physical contradiction: the attenuation time of automobile vibration can not be too long or too short.

The attenuation time is too short, it is easy for the passengers to feel the violent vibration, and the attenuation time is too long, which is not conducive to the vehicle handling stability. Fourth steps: The teacher inspired students to find available resources: air suspension, hydraulic suspension, seat material, etc.

Fifth steps: Using TRIZ tools -- innovation principle, separation principle and so on. According to the technical contradictions existing in the system, four innovative principles are searched out in the TRIZ contradiction matrix (21, 24, 29, and 40):

Innovation principle 21: reduce the harmful effect of time;

Innovation principle 24: with the aid of intermediary;

Innovation principle 29: air pressure and hydraulic structure;

Innovation principle 40: composite materials;

Sixth steps: Inspire students to generate new ideas and technical implementation program: Based on the principle of innovation, inspired students can use air suspension or hydraulic suspension system, can make comfort and operation stability to achieve balance, meet comfort.

Seventh step: students can enter the laboratory after class to carry out experiments and demonstration.

\section{The Possibility of Applying TRIZ Theory to Creative Teaching in Our University}

\subsection{In Line with the Engineering Oriented Application Oriented Undergraduate Colleges and} Universities Education Training Concept.

Throughout the development of education and teaching in Colleges and universities, innovative education generally stays at the stage of theoretical exploration and conceptual change, but there are still few effective methods at the practical level. Guilin Institute of space industry, as one of the Application-oriented Undergraduate Colleges and universities, aims to cultivate scientific and technological talents with strong innovation ability, and to improve the teaching of College Students' innovative ability is the key point of school teaching reform. Therefore, an urgent need to let student's innovation ability in teaching and practice in the classroom and the system theory, TRIZ theory is an effective tool to meet the requirements.The cultivation of these abilities is just in line with the TRIZ theory and the way of operation.

\subsection{Ideological Shackles Conducive to Breaking through Old Ideas.}

For a long time, people generally think that innovation is one of the few talents of the patent, or it is accidental strike a spark of inspiration and opportunity, actively hindered the implementation of innovative education and normal development. In essence, the ability to innovate should be a kind of analysis and problem-solving thinking, which can be taught and learned. TRIZ theory provides people with systematic innovation theory and scientific thinking method, which plays an important 
role in inspiring creative thinking and exploring ways of thinking. Many colleges and universities in Europe that years of practice, improve teaching methods, teachers not only impart knowledge, and how to inspire innovation into the classroom, let the students to change the mindset, multi angle thinking, so as to find a new and more scientific way to solve the problem, TRIZ is in the modern innovation ability raising great contribution on the path.

\section{Thoughts and Suggestions Based on TRIZ Theory Teaching}

\subsection{Implementing TRIZ Theory and Educational Methods for Teachers.}

It is the premise and foundation of carrying out innovative education to train teachers with innovative spirit and master innovation theory and method. In order to extend the TRIZ theory to the teaching practice of Guilin Institute of space industry, it can be carried out in two steps:

First of all, select some outstanding young teachers to participate in TRIZ theory training inside and outside the school, first let some teachers master the essence and key points of TRIZ theory and teaching methods;

Secondly, combining with the teaching reform of practical experience, the preparation of school-based teaching materials, pilot, set up TRIZ theory teaching team, the establishment of TRIZ Theory Education Research Center, batches organization theory and application of teachers to participate in training, the teachers of our school to promote TRIZ technology to help teach theory, ideas and methods of Shi Tuokuan teaching, classroom teaching and practice to stimulate students' innovation ability.

\subsection{Adopting Small Class System and Interactive Teaching.}

Restricted by the teachers, most colleges and universities set up TRIZ related theory courses are taught in large classes, mainly teaching, lack of interaction and discussion. And the real thinking innovation, just like learning to drive, coach teaching methods, students should practice, practice constantly to truly master the driving skills, or else just on paper. TRIZ is suitable for course teaching in small classes that provide students with more opportunities to participate in the teaching process, and answer questions through the interaction between teachers and students, will be thinking combined with inspiration to guide and help students to learn as the embodiment of the subject, but also help teachers to understand students' feedback.

\subsection{Designing TRIZ Teaching Course System by Stages.}

The teaching idea and method of TRIZ theory and practice in the aerospace industry, Guilin of science and engineering undergraduate teaching, students need to master the knowledge and cognitive ability development design and implementation stage, consider constructing curriculum system as follows in Fig.1.

The car as an example, the first stage: students learning courses in basic theory course, the computer curriculum for compulsory course arrangement of the stage of undergraduate teaching, at this stage for the introduction of the TRIZ theory of inspiration, should carry out special TRIZ innovation ability development course, and highlight the prototype elicitation in the basic theory course of study and, with computer aided innovation software to complete the task of learning, innovation and inspiration.

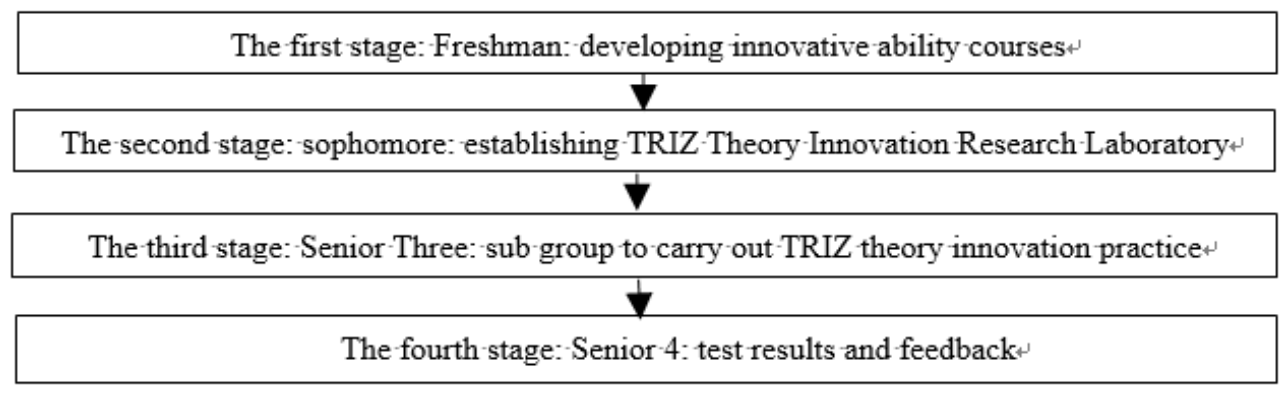

Fig 1 . TRIZ theory and practice 
The second stage: students learning courses in the theory courses of mechanical basis, compared with the big stage, has gradually turned to professional categories of learning, the establishment of automobile TRIZ theory innovation research laboratory, the TRIZ technology into the teaching in the classroom and after-school students to participate in innovative experiments combining theory and practice, to complete the TRIZ task.

The third stage: the student has entered into the core curriculum combined with automotive professional learning courses, teachers have more skilled teaching TRIZ skills, TRIZ technology is inspired from the theoretical teaching and experimental teaching, and participate in the opening experiment group into the laboratory, to complete the course design work in practical work oriented innovation college students, encourage students to participate in the "Challenge Cup" "innovation design competition" competition, to promote the completion of works in the game.

The fourth stage: students of the innovative design in the application of TRIZ curriculum design, graduate design theory, graduation design to overcome the phenomenon of plagiarism, reduce the repetition rate of the graduation design, improve the quality of graduation design, and test and feedback in the practice base, improve the innovative design, to solve the actual problems encountered in the design process, gradually realize from the creation, the concept of creation to innovation of education purpose, methods, teaching methods and curriculum system of the education mode, finally completed the test results and feedback task. Teachers also check the effectiveness of TRIZ teaching methods in the acceptance of works.

\subsection{Using TRIZ Theory to Improve Teaching Plan and Improve Teaching Skills.}

In the course of introducing TRIZ theory, teachers should make clear the main line of teaching, clear teaching programs, improve teaching methods and skills. The design of teaching contents, to always maintain the advanced nature, timely reflect and absorb the latest research results of the academic field, actively integrating outstanding teaching achievements, increase the level of modern technology, can reflect the professional characteristics of the experiment, increase the comprehensive and design experiment, 40 adopts TRIZ theory creation method in principle. And the cultivation of students'creative thinking. Design of teaching methods, to teaching method, discussion method, competition law, combat training teaching methods, guide students in inquiry learning, discussion based learning case based and participatory project based learning problems based on the future has occurred or may occur as case form for students put forward a variety of solutions to the problem, let the students to learn actively and boldly speak their thinking, to overcome the inertia of thinking, cultivate the scientific spirit of the way of thinking.

\subsection{Adopting Innovative Achievement Oriented, Process Evaluation and Result Evaluation}

\section{Combined Curriculum Assessment Methods.}

Objective to carry out TRIZ theory teaching is to cultivate students' innovative thinking and ability, with written traditional methods obviously can not comprehensive assessment of the effectiveness of teaching and learning is not conducive to mobilize the enthusiasm and initiative of students, therefore, must pay attention to the teaching process, the evaluation and the evaluation process of the organic combination. In the classroom, the teacher can ask students to choose a TRIZ method is used to solve the problem (project), in the subsequent course, try TRIZ innovative methods and tools for using learning to solve this problem, and help students to understand the digestive process of knowledge, students will be required after the course to solve problems in TRIZ theory and get the solution form a summary report. The final score can be composed of the following parts: (20\%) the completion of class performance, homework (20\%), (20\%), the respondent course report summary report (40\%), which reflects the importance of the process and the results come out.

\subsection{Multiage, Multidisciplinary, Multi form Promotion of Tris Learning.}

It Can Be Taught By TRIZ Theory As A chapter in the course of mechanical innovation design; it can also be taught as a chapter in the course of innovation and entrepreneurship in the course of career guidance; it can also be set up independently as an elective or restricted course, or in the form of a lecture, short term training, and TRIZ theory in the form of a student community. The popularization and application of TRIZ theory. But as the engineering department, the principle requires 
organization set up "innovative thinking training" and "innovation and invention", "TRIZ" and other theory professional elective courses or professional courses, introduces the basic principle and innovation of TRIZ theory, and some examples of the application of the theory to solve the problems in practice, enhance the enthusiasm and the consciousness of the students in their creative design, make students become the discoverer and explorer, researchers and innovators. For non engineering students, teaching content to TRIZ innovative thinking, resource analysis, causal analysis method as the focus, in case of life, pay attention to grasp the essence of the method of the invention, the confusion and disorder of students innovation, improve the quality and ability of innovation.

\section{Summary}

Scientific research and practice show that every student has creative thinking and creative ability, but most of the students are in a state of sleep or half sleep because of the influence of the objective conditions and their own factors. We should focus our attention on every student and take the way of induction and inspiration to excavate their potential wisdom. In order to build an innovative education curriculum Institute based on TRIZ theory and explore the training mode of innovative applied talents, based on the implementation of innovation theory and education method, teaching practice, competition practice and scientific research practice as the link, and taking the patent results as the goal, TRIZ will be a method of promoting the future. It can be further perfected in the practice of the new mode of College Students' innovative education.

\section{Acknowledgments}

This work is carried out with the support of the project "research and practice of CDIO based project driven Teaching in the innovative and entrepreneurial education of applied undergraduate engineering talents" in 2017 Guangxi higher education undergraduate teaching reform project (2017JGB428), the ideological and political theory and practice project of the University of Guangxi in 2015, innovation and creation of students in Applied Undergraduate Colleges Based on TRIZ theory The research on the curriculum system of the industry (2015LSZ021) and the research fund project of the Guilin Aerospace Industry Institute in 2014, "Research on the cultivation of innovative and entrepreneurial culture of students in Applied Undergraduate Colleges and Universities Based on TRIZ theory" (YJ1417). "The construction and practice of the curriculum system of automobile inspection and maintenance specialty based on the cultivation of post professional ability" (NO.GXGZJG2016A058).

\section{References}

[1]. Yang Singling, the invention was born in this way: TRIZ theory is fully exposed to [M], Beijing: Machinery Industry Press, 2006:7.

[2]. Zhao Min, Shi Xiaoping, Duan Haibo, TRIZ introduction and practice [M]. Beijing: Science Press, 2009:12. 